RESENHA

\title{
Culturas infantis e desigualdades sociais
}

\author{
Daniela de Oliveira Guimarães' (D) \\ Nubia de Oliveira Santos' (ID
}

\begin{abstract}
ARENHART, Deise. Culturas infantis e desigualdades sociais. Petrópolis: Vozes, 2016.
\end{abstract}

No Brasil, os estudos da Infância e da Educação Infantil ampliaram-se nas últimas décadas. Esse movimento é fruto do reconhecimento das crianças como cidadãs de direito e da Educação Infantil como primeira etapa da Educação Básica (Brasil, 1996). Nesse cenário, os campos da Sociologia da Infância, assim como os aportes da Antropologia, permitem a compreensão alargada das culturas infantis, possibilitando novos contornos às pesquisas e às ações educacionais com as crianças de 0 a 6 anos. Ganham relevo as pesquisas com crianças, nas quais elas são consideradas na perspectiva da alteridade, ou seja, como sujeitos sociais diferentes dos adultos (e não hierarquicamente inferiores), agentes sociais. A participação infantil e os estudos das crianças a partir de si mesmas marcam diversas análises das experiências sociais das crianças brasileiras.

O livro Culturas infantis e desigualdades sociais, de autoria de Deise Arenhart, traz uma importante contribuição nesse contexto, na medida em que evidencia as práticas culturais de dois grupos de crianças em realidades sociais diversas.

Prefaciado por Manuel Jacinto Sarmento e publicado, em 2016, pela editora Vozes, o livro é um desdobramento da tese de doutorado da autora e teve como questão propulsora a indagação sobre a produção das culturas das crianças, e o que elas indicam, simultaneamente, sobre seu pertencimento geracional — relacionado às condições comuns postas à infância - e sobre seu pertencimento social - relativo a condições objetivas diferenciadas e desiguais de vida.

O estudo foi realizado em três instituições de Educação Infantil no Rio de Janeiro com dois grupos de crianças de 4 a 6 anos que diferem entre si pela posição de classe; ou seja, um grupo de crianças empobrecidas, moradoras de uma favela no Rio de Janeiro, e outro grupo, oriundo de classe média-alta, de crianças pertencentes a famílias de expressivo capital cultural.

O livro é dividido em 5 capítulos. Nos dois primeiros, a autora discute referenciais teóricos que ancoram a análise das relações entre Infância e Cul-

'Universidade Federal do Rio de Janeiro, Rio de Janeiro, RJ, Brasil. 
tura; também, descreve as escolhas metodológicas, o processo de entrada no campo de pesquisa e o próprio campo e suas peculiaridades. Nos capítulos seguintes, as reflexões sobre a empiria são desenvolvidas, destacando-se o lugar do corpo e da brincadeira bem como as condições de desigualdade nas experiências infantis.

O primeiro capítulo, "Caminhos que levam às crianças e suas culturas", apresenta a perspectiva da Sociologia da Infância na consideração das crianças como sujeitos da e na cultura. Nesse movimento, são importantes a sinalização do desvio de uma ideia de socialização vertical, dos adultos em relação às crianças, e a consideração da socialização numa perspectiva horizontal, a partir da qual entendemos que as crianças socializam-se entre si. Nessa trilha, no diálogo com William Corsaro, focaliza a brincadeira como reprodução interpretativa, por meio da qual as crianças reiteram a cultura adulta dominante, ao mesmo tempo em que a reinventam com suas ações criativas.

De modo especial, a partir do conceito de habitus de Pierre Bourdieu, a autora define a divisão de classe que marca os dois grupos de crianças que compõem o estudo. Para esse interlocutor, a posse e o volume de diferentes capitais (econômico, social, cultural e simbólico) definem e hierarquizam a posição dos agentes na sociedade. Ao mesmo tempo, o habitus é o conjunto de disposições práticas adquiridas pelo sujeito em seu processo de socialização que garante o pertencimento a determinada cultura e classe. Por esse prisma, Arenhart (2016) distingue o grupo de crianças "do castelo", que dispõe de maior volume de capital econômico e cultural, pertencendo à classe média alta/intelectualizada e constituindo-se no que é reconhecido como classe dominante. Por outro lado, o grupo "da favela", que se enquadra como classe popular, apresentando desvantagens em relação a todos os tipos de capitais.

Nesse contexto, é importante a distinção que Arenhart (2016) faz entre diferenças e desigualdades. Se, por um lado, é fundamental identificar as diferenças que marcam as construções culturais das crianças, quanto ao pertencimento geracional, por outro lado, as condições de classe expõem, para além das diferenças, as situações de desigualdade que experimentam as crianças em distintas condições materiais e simbólicas de vida. As diferenças convertem-se em desigualdades, quando, fruto de nosso processo histórico, influenciam e expressam-se no maior ou menor acesso a bens e oportunidades.

Ainda no primeiro capítulo, a autora expõe de modo consistente e vivo, o movimento de entrada no campo, a partir da perspectiva etnográfica que orienta o estudo, efetivado em sistemáticas sessões de observação das interações infantis e registros em diário de campo, além de entrevistas com crianças e famílias. Assim, não só o equacionamento entre proximidade e distância das crianças é focalizado, evidenciando a importância da convivência e de se estar próximo delas para compreender como produzem significados partilhados, mas também o desafio da reflexividade e da construção de sentidos sobre a empiria. Vigilância epistemológica, entrega e sensibilidade são apontadas como movimentos importantes na construção de um entrelugar como pesquisadora, "nem a típica adulta, dona do poder, nem o cameleão, se passando por criança” (Arenhart, 2016, p. 49). 
Nessa trilha, a aposta da autora caminhou na direção de uma relação de confiança e de experiência compartilhada que ela encontrou na brincadeira. Aqui reside uma questão fundamental no trabalho de Arenhart, o brincar como pressuposto teórico e metodológico imprescindível para, como afirma a própria autora, "afinar a percepção sobre as crianças da pesquisa” (Arenhart, 2016, p. 51).

Os conflitos da pesquisadora, assim como as dificuldades que perpassaram a metodologia adotada, são explicitados de forma clara e honesta e apontados como uma forma intencional de mostrar que é a entrada em campo que vai indicando não somente os desafios e os dilemas do pesquisador, mas também os caminhos da pesquisa.

O segundo capítulo, "Entre a favela e o castelo: apresentando as crianças e seus contextos de vida", situa o leitor acerca dos contextos de vida em que as crianças pesquisadas estão inseridas, tanto a família quanto a escola. Esses são levados a cabo nas análises empreendidas ao longo do livro, em que a autora não abandona os elementos estruturais que se relacionam à agência das crianças.

O terceiro e quarto capítulos "Corpo-criança: o que se vê quando se olha" e "Brincadeiras e culturas infantis: a influência dos contextos sociais", são recheados de eventos vivos e densos da experiência de observação da autora, revelando um rigor teórico metodológico no diálogo entre a empiria e a teoria.

$\mathrm{Na}$ perspectiva da corporeidade, Arenhart considera as marcas do pertencimento geracional, indicativas da chamada "cultura designadamente infantil", reveladoras de um modo próprio e distinto dos modos de relação corporal dos adultos. Em segundo lugar, faz o movimento de identificar e analisar como essas relações, inicialmente comuns entre as crianças e diferentes dos adultos, também evidenciam a posição social das crianças e sua condição de diferença e desigualdade. O corpo é analisado como linguagem e interação; resistência e transgressão; experiência lúdica e fonte de agência e poder.

No quarto capítulo, a autora retoma o objetivo do livro trazendo a brincadeira como principal ponto de análise, resgatando a forma como crianças de grupos sociais distintos se relacionam e constroem cultura brincando e, especialmente, como suas brincadeiras manifestam relação com elementos estruturais como classe e geração, bem como lugar geográfico, cultura escolar, familiar e midiática, posições de gênero, etc.

A brincadeira é considerada como base da cultura de pares das crianças, o que é evidenciado pelo protagonismo que elas adquirem na criação de contextos lúdicos e na organização social que experimentam para mobilizar e proteger o espaço do brincar. Assim, a autora vai mostrando que as práticas rotineiras de brincadeiras formam a cultura lúdica das crianças e fortalecem o sentido de pertença a um grupo de pares.

A obra de Arenhart parece abarcar diversas possibilidades de análises do brincar a partir da sua experiência nas escolas de Educação Infantil com aqueles dois grupos de crianças. Entretanto, a autora é rigorosa ao não perder o foco da perspectiva das culturas da infância. Sem perder esse prisma, a pesquisadora analisa as relações sociais empreendidas no brincar, revelando, por exemplo, as relações de posse e poder entre as crianças. 
Por fim, "Culturas infantis em contextos desiguais: para onde no leva esse debate"? apresenta-se como pergunta final e título do quinto capítulo. A autora fecha o livro retomando as questões mobilizadoras da pesquisa. Arenhart (2016) articula sua compreensão de como as culturas infantis expressam a condição de classe social e geração inerente às crianças com a análise de como os contextos sociais diferentes e desiguais - e, neles, a escola - contribuem para possibilitar e ou limitar processos de reprodução interpretativa pelas crianças, decisivos para que elas se exerçam como atores culturais.

O livro de Deise Arenhart (2016) é um convite ao mergulho nos estudos do campo da Sociologia da Infância, em que as categorias corpo e brincadeira e suas relações com as culturas infantis nos ajudam a compreender as crianças em suas práticas culturais.

\section{REFERÊNCIAS}

ARENHART, D. Culturas infantis e desigualdades sociais. Petrópolis: Vozes, 2016. BRASIL. Lei no 9.394, de 20 de dezembro de 1996. Estabelece as Diretrizes e Bases da Educação Nacional. Diário Oficial da União, Brasília, 1996. Disponível em: http:// www.planalto.gov.br/ccivil_03/leis/L9394.htm. Acesso em: 13 dez. 2019.

\section{SOBRE AS AUTORAS}

Daniela de Oliveira Guimarães é doutora em educação pela Pontifícia Universidade Católica do Rio de Janeiro (PUC-Rio). Professora da Universidade Federal do Rio de Janeiro (UFRJ).

E-mail: danguimaraes@uol.com.br

Nubia de Oliveira Santos é doutora em educação pela Universidade do Estado do Rio de Janeiro (UERJ). Professora da Universidade Federal do Rio de Janeiro (UFRJ).

E-mail: nubiasantos.fe.ufrj@gmail.com

Recebido em 29 de fevereiro de 2020

Aprovado em 12 de junho de 2020 